\section{Mixed Crystals of Threonine and Allothreonine}

\section{Koji ToI and Naotake SATo}

Central Research Laboratories, Ajinomoto Co., Inc., Suzuki-cho, Kawasaki

Received October 16, 1974

We report here the formation of mixed crystals between threonine and allothreonine, which was found in the course of studies on the separation of L-threonine from a synthetic mixture of threonine.

The synthetic threonine is a mixture of four epimeric isomers, D- and L-forms of threonine and of allothreonine. An attempt to separate $\mathrm{D}$ - and $\mathrm{L}$-threonine from the synthetic mixture was made by a preferential crystallization procedure. The separation was tried in a fluidized bed system, which consisted of two columns connected in parallel and charged separately with seed crystals of D- and L-threonine. A supersaturated aq. solution of the synthetic threonine mixture was continuously passed through the columns to make the seed crystals grow. The grown crystals of $\mathrm{D}$ - and L-threonine were analyzed by paper chromatography, which showed that they were always contaminated with allothreonine.

The allothreonine in the grown $\mathrm{D}$ - and L-threonine were isolated by use of paper chromatography. The allothreonine isolated from $\mathrm{D}$-threonine showed its optical rotation of $(-)$, indicating $D$-allothreonine, and the one from L-threonine, of $(+)$, indicating L-allo-

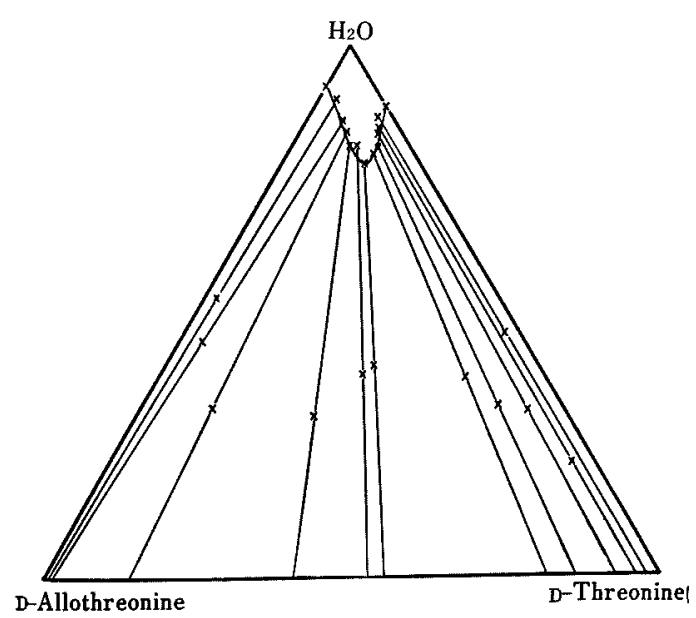

FIG. 1. Ternary Phase Diagram for the System Consisting of D-Threonine, D-Allothreonine and Water at $50^{\circ} \mathrm{C}$.

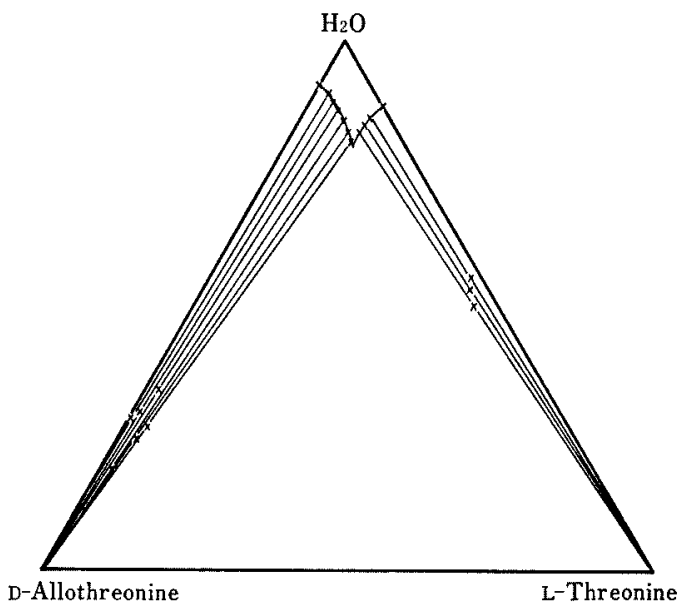

FIG. 2. Ternary Phase Diagram for the System Consisting of L-Threonine, D-Allothreonine and Water at $50^{\circ} \mathrm{C}$.

threonine. This fact suggested that $\mathrm{D}$-threonine easily forms mixed crystals selectively with $\mathrm{D}$-allothreonine, and L-threonine with L-allothreonine.

Thus, the ternary phase diagram for a system consisting of $\mathrm{D}$-threonine, $\mathrm{D}$-allothreonine and water was plotted at a constant temperature $\left(50^{\circ} \mathrm{C}\right)$. Figure 1 shows the case in which these two isomers form solid solution or mixed crystal in the solid state. The tie lines in the two phase region connect compositions of solid and liquid in equilibrium with one another. Exactly the same relation was obtained with a system consisting of L-threonine, L-allothreonine and water.

The ternary phase diagram for the system of Lthreonine, D-allothreonine and water was also plotted in the same manner. Figure 2 shows the case in which these two isomers exist as a mixture in the solid state, with the tie lines in the two phase regions connecting the equilibrium compositions of the co-existing phases. The same relation was obtained with the system consisting of D-threonine, L-allothreonine and water.

From the experimental results described above, it was elucidated that $\mathrm{D}$-threonine and $\mathrm{D}$-allothreonine, or L-threonine and L-allothreonine form mixed crystals with arbitrary ratios. On the other hand, D-threonine and $\mathrm{L}$-allothreonine, or $\mathrm{L}$-threonine and $\mathrm{D}$-allothreonine exist as a mixture in the solid state.

\section{EXPERIMENTAL}

Determination of threonine and allothreonine. Determination of threonine and allothreonine was conducted by paper chromatography. The paper chromatogram (Toyo Roshi No. 51) developed in a solvent system of $n$-butanol-methyl ethyl ketone-conc. ammonia - water $(5: 3: 1: 1)$, ${ }^{11}$ was stained with the ninhydrin- 
cadmium reagent. ${ }^{2)}$ Two spots corresponding threonine and allothreonine were cut out and separately eluted with methanol. The absorbance of the eluate was measured at $510 \mathrm{~nm}$.

Separation of $D$ - and L-threonine from synthetic threonine mixture. A fluidized bed system was made of two columns connected in parallel. The column, $8 \mathrm{~cm}$ long and $2 \mathrm{~cm}$ diameter, was separable in the middle and fitted with sintered glass discs at both ends. Seed crystals ( $1.0 \mathrm{~g}, 28 \sim 50$ mesh) of D-and L-threonine were added separately to each column. A supersaturated aq. solution containing $28.1 \%$ of DL-threonine and $11.9 \%$ of allothreonine, was continuously passed through the columns over a period of $4 \mathrm{hr}$ at a constant temperature $\left(60^{\circ} \mathrm{C}\right)$ and a constant flow rate $(300 \mathrm{ml}$ per min). The grown crystals in each column were separated by filtration. The weights and optical rotation values of the grown D- and L-threonine were $4.9 \mathrm{~g}$ and $5.2 \mathrm{~g}$, and $[\alpha]_{\mathrm{D}}^{25}-18.9\left(c=2, \mathrm{H}_{2} \mathrm{O}\right)$ and $[\alpha]_{\mathrm{D}}^{25}+18.9$ $\left(c=2, \mathrm{H}_{2} \mathrm{O}\right)$, respectively.

Separation of allothreonine from the grown $D$ - and $L$-threonine. The grown crystals of $\mathrm{D}$ - and $\mathrm{L}$-threonine $(0.1 \mathrm{~g})$ was dissolved in water $(2 \mathrm{ml})$ and the solution was applied on a thick filter paper (Toyo Roshi No.527, $40 \times 40 \mathrm{~cm})$ as a narrow band $(1 \times 36 \mathrm{~cm})$. The paper was chromatographed for $16 \mathrm{hr}$ using a solvent system of $n$-butanol-methyl ethyl ketone-conc. ammoniawater $(5: 3: 1: 1)$. The allothreonine zone was cut out and eluted with $2 \mathrm{~N}$ ammonia. The eluate was evaporated to obtain the allothreonine. The same procedure was repeated. The optical rotation of the combined allothreonine was measured. The allothreonine separated from the grown crystals of $\mathrm{D}$ - and L-threonine showed $[\alpha]_{\mathrm{D}}^{25}-8.2\left(c=2, \mathrm{H}_{2} \mathrm{O}\right)$ and $[\alpha]_{\mathrm{D}}^{25}+7.9(c=2$, $\mathrm{H}_{2} \mathrm{O}$ ), respectively.

Ternary phase diagrams. Arbitrary amounts of Dthreonine and $\mathrm{D}$-allothreonine were added in $10 \mathrm{ml}$ of water and dissolved at $75 \sim 80^{\circ} \mathrm{C}$. After filtration, the solution was stirred for $3 \sim 4 \mathrm{hr}$ at $50^{\circ} \mathrm{C}$. The solid crystallized out was separated by filtration. The amounts of threonine and allothreonine in the solid and liquid phases were determined and plotted in the diagram (Fig. 1).

The diagram for the case of L-threonine and D-allothreonine was made in the same manner (Fig. 2).

\section{REFERENCES}

1) H. Geipel, J. Gloede, K. P. Hilgetag and H. Gross, Chem. Ber., 98, 1677 (1965).

2) J. Heilmann, J. Barrollier and E. Watzke, $Z$. Physiol. Chem., 309, 219 (1957). 